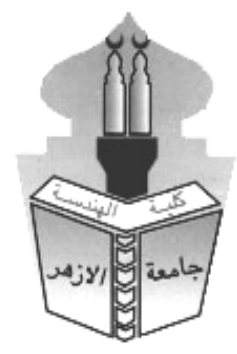

\title{
STUDY THE EFFECT OF GREEN SPACES AND PUBLIC SPACES IN IMPROVING THE QUALITY OF CITIES LIFE- HOLY MAKKAH AS CASE STUDY BASED ON THE URBAN OBSERVATORY INDICATORS
}

\author{
Ali Abd Allah Elmansoury ${ }^{1}$ and Mohieldin Ahmed Muhammad Hawary ${ }^{2}$ \\ ${ }^{1}$ Architectural Department, College of Engineering, Al-Azhar University, Egypt \\ Ail.elmansory@azhar.edu.eg \\ ${ }^{2}$ The Nile Higher Institute of Engineering and Technology -El Mansoura \\ mohiyr@yahoo.com
}

\begin{abstract}
Providing cities with green urban spaces should be one of the most important goals for city planners, decision-makers and urban designers. The research devised several results to assess the current situation to study urban spaces and green areas, with recommendations on designing and developing urban spaces with more green areas for the city of Makkah AlMukarramah. The research is utilizing urban indicators produced from the Urban Observatory of Makkah and compare them with other Urban Observatories' indicators in the Kingdom (Riyadh Observatory - Dammam Observatory - Jeddah Observatory - Taif Observatory Buraidah Observatory.

research problem: In light of the lack of interstitial spaces within the urban cluster of residential areas, the problem lies at the lack of green spaces and open urban spaces within residential areas for residents to practice various life activities. This become more complicated when it comes to areas of high value such (The central area) and the neighboring residential areas, particularly with the increase in the population density and the continuous movement of residents and visitors to Makkah.

The aim of the research: Through studying the indicators of the Urban Observatory of Makkah and compare it with other urban observatories in the Kingdom With great concern to the quality of life indicators, the indices of green areas and public open places, the research aims to propose solutions that disseminate a culture of green areas and open urban spaces, besides, to shed light and direct the attention of decision-makers and stakeholders to adopt green concepts that can provide a safe and stable quality of life.

Research hypothesis: Although the studies through urban observatories for urban indicators at the Kingdom for green areas and open spaces on the city level are available, these public spaces may not meet the needs of users and lacks the focus on indicators for human needs.

\section{Research Methodology:}

Theoretical study: The research reviews the concepts of green spaces and concepts of quality of life besides studying the goals of establishing urban areas and how to respond to human needs and accommodate the required activities and their contribution to support the concept of the quality of city life.

Analytical studies: The research analyses the indicators of the urban observatory in (Makkah Al-Mukarramah) region, focusing on indicators of the quality of life and studies some open urban spaces in some neighborhoods and cities of the Makkah region to identify the needs and patterns of behavior for users in addition to the reasons leading to the use of the space or not.
\end{abstract}

Keywords: parks, gardens, green spaces - the quality of life - urban indicators - open public spaces 


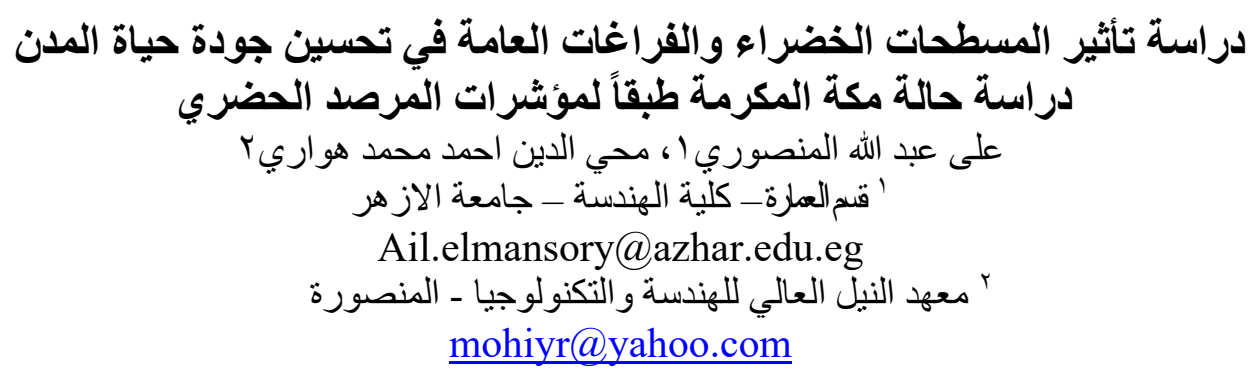

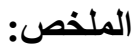

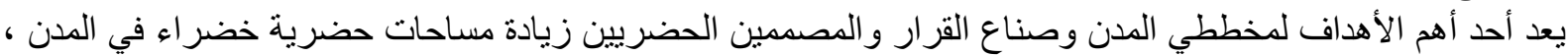

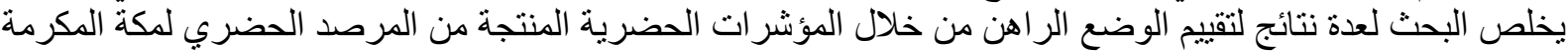

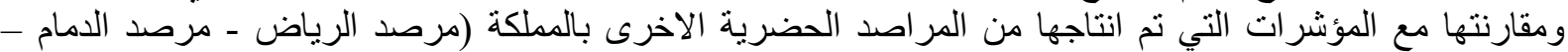

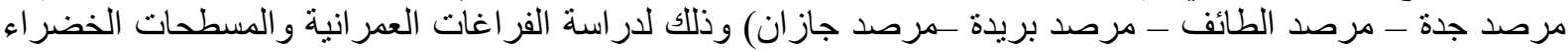

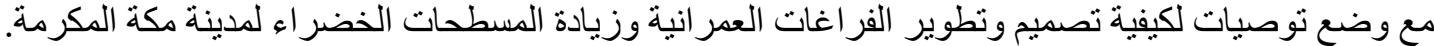

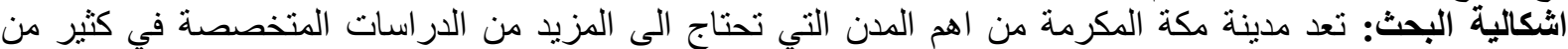

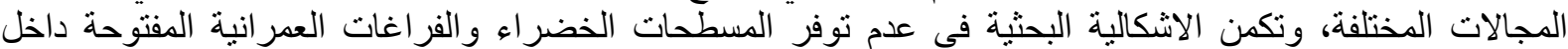

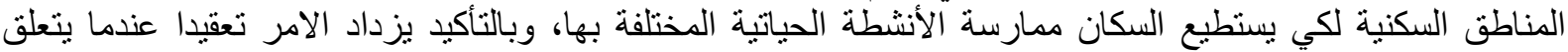

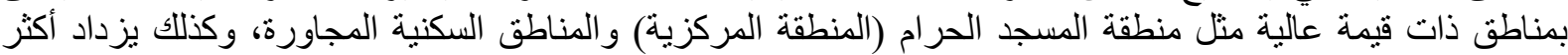

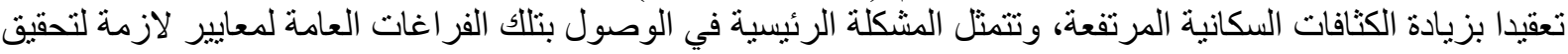

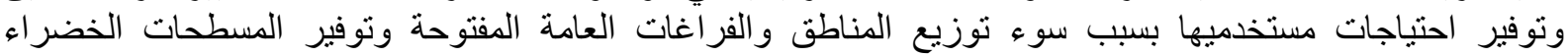

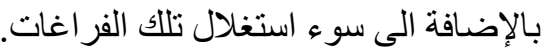

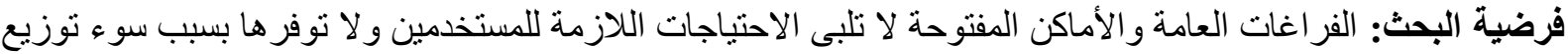

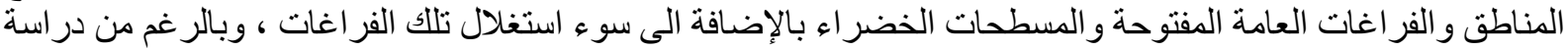

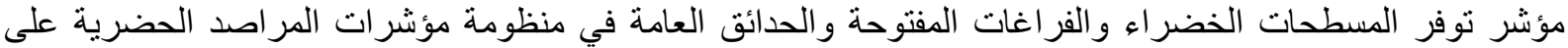

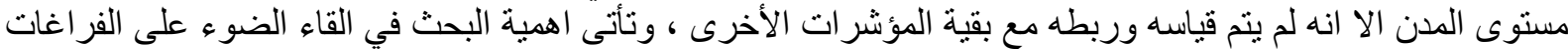

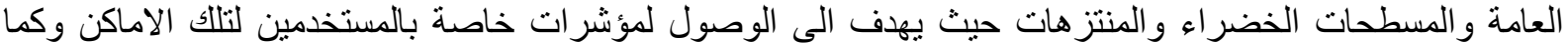

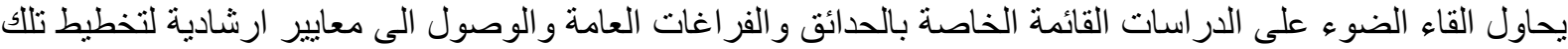

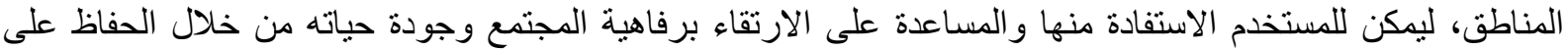

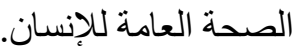

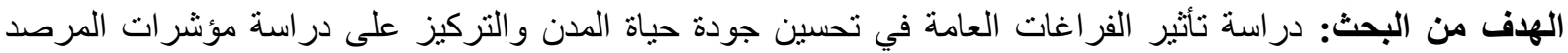

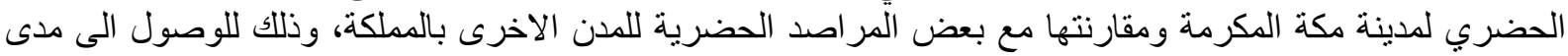

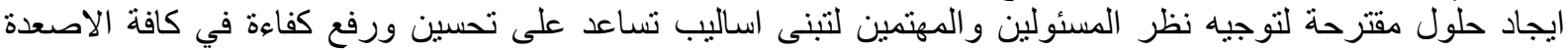
لتوفير جودة حياة آمنة ومستقرة. منهجية البحث: منهج نظري استقر ائي: اعتمد البحث علي المنهج الاستقرائي من خلال تجميع در اسات نظرية قر ائية سابقة

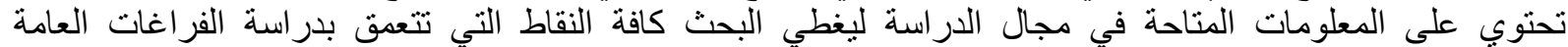

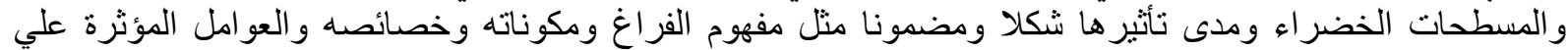

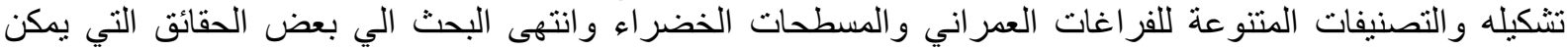

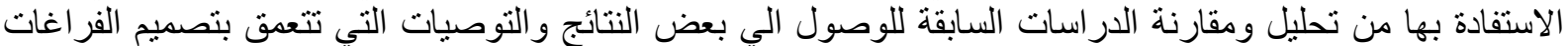

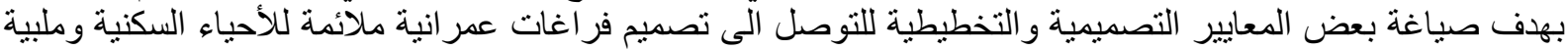

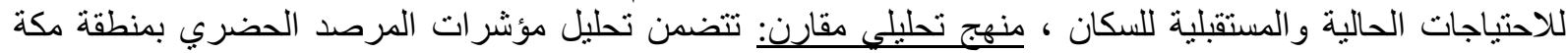

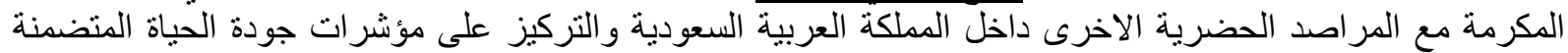
ودر اسة بعض فر اغات عمر انية مفتوحة ببعض الحياء ومدن منطقة مكة المكرمة للتعرف على على احتياجات و وانماط السلوك

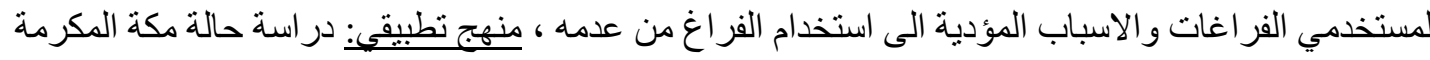

الكلمات الدالة: المنتزهات و الحدائق و المسطحات الخضر اء ـ جودة الحياة ـ المؤشرات الحضرية ـ الفراغات العامة المفتوحة - رفاهية المجنمعات. 
تعتبر الفر اغات الحضرية والمسطحات الخضر اء إحدى أهم عناصر التكوين الحضري في المدن، وهي مهمة جد لسكانها

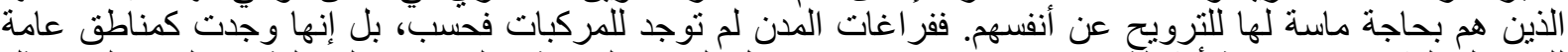

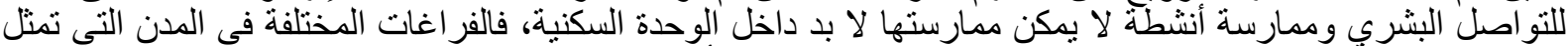

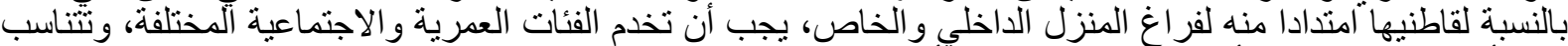

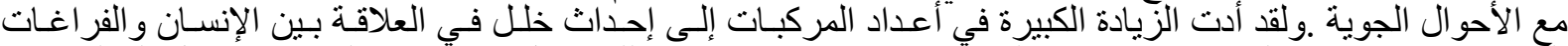

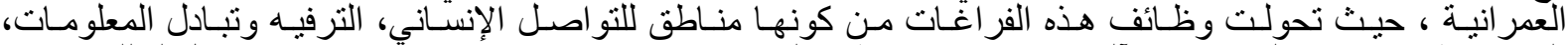

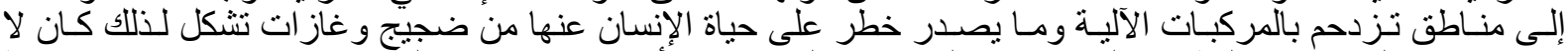

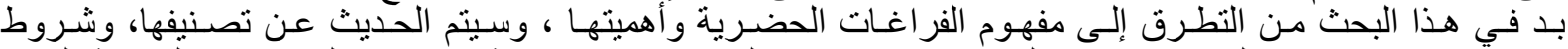

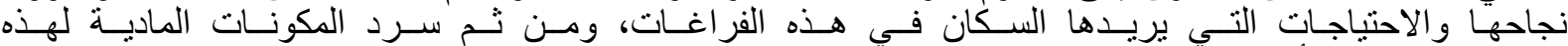

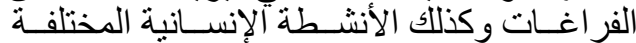

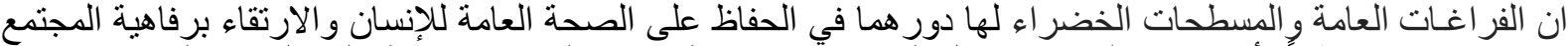

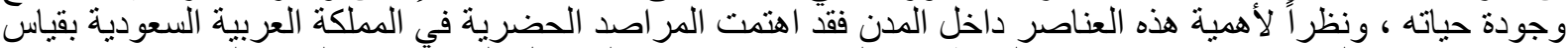

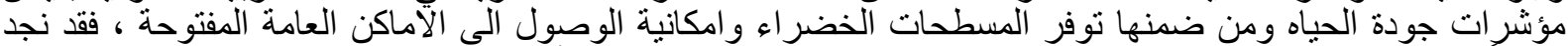

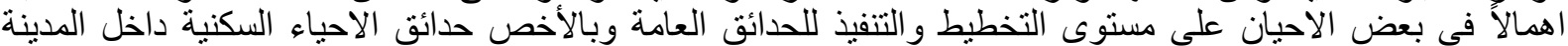

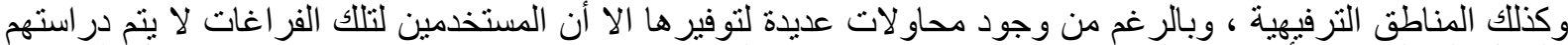

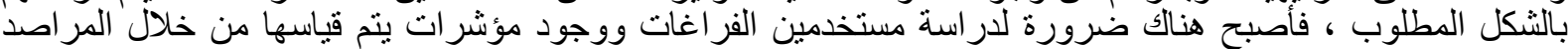
الحضرية القائمة. ولقد بدأت العناية ببر امج المؤشرات الحضرية على مستوى عالمي من خلال برنامج الأمم المتحدة للمستوطنات البشرية

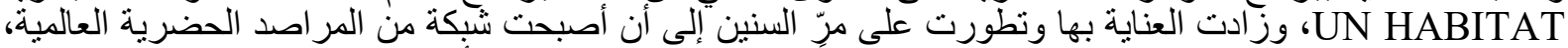

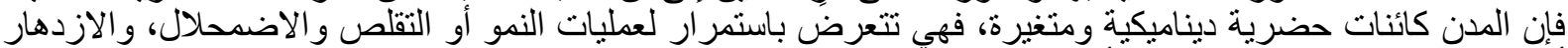

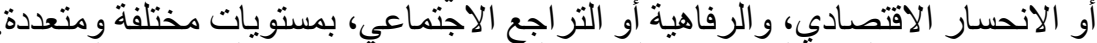

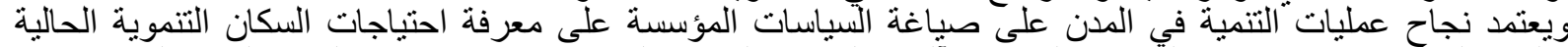

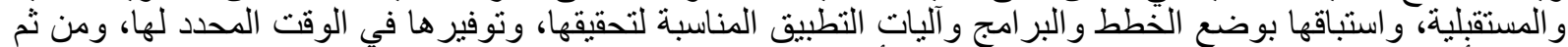

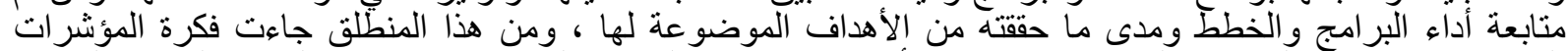

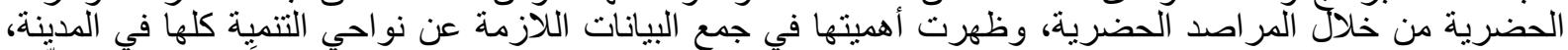

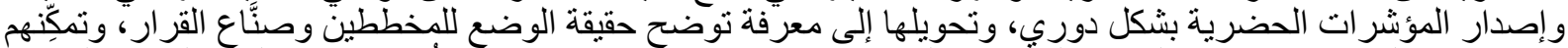

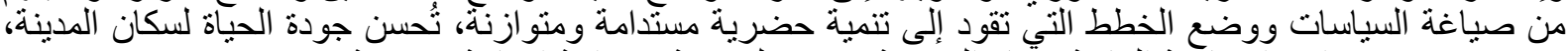

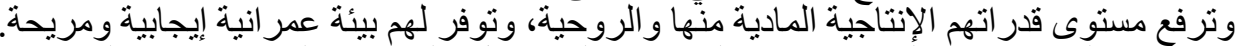

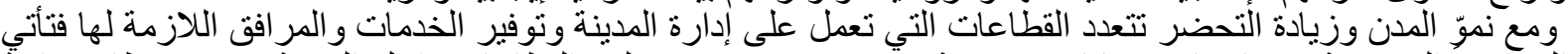

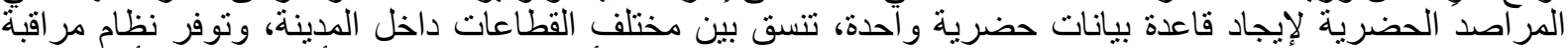

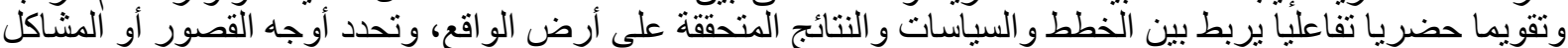

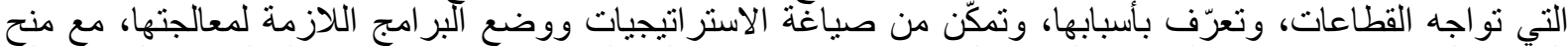

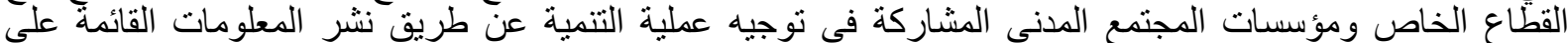

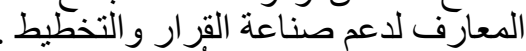

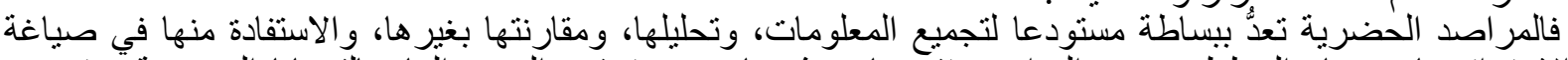

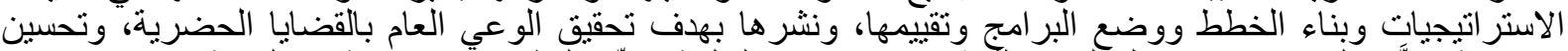
مصداقية صنَّاع القرار، وفتح مجال الحوار للحّدِّ من الاتجاهات السلبية وتبنِّي التطبيقات الإيجابية في التنمية.

/ / مفاهيم وتعاريف:

$$
\text { 1/1 المؤشرات الحضرية: }
$$

تعد المؤشرات الحضرية أحد الآليات الفعالة لقياس مدى التقدم المستهدف للمستقرات الحضرية صوب النتائج المنشودة

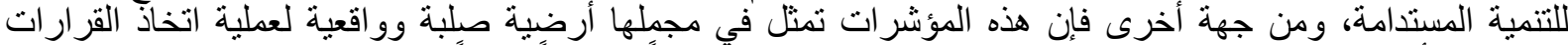

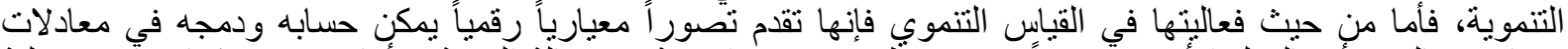

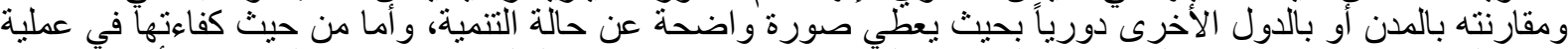

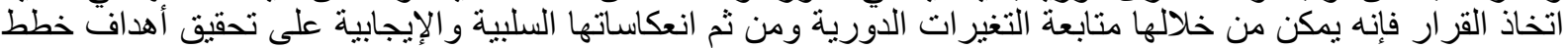

التنمية الحضرية.

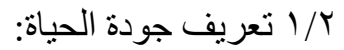

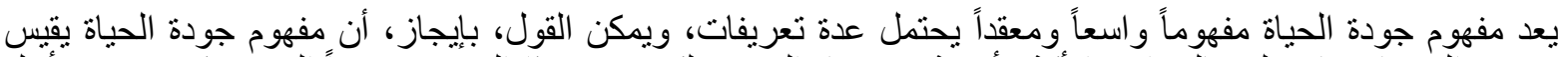

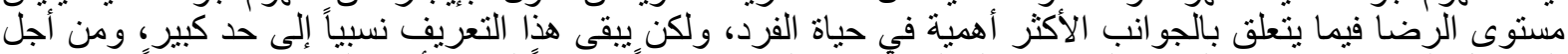

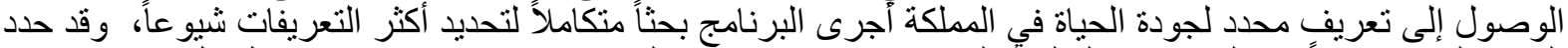

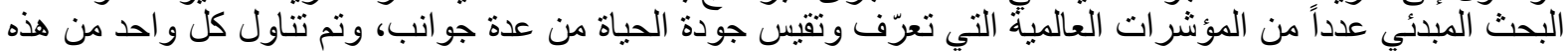


المؤشر ات بشكل تفصيلي من أجل تحديد العناصر المشتركة ، اعتمدنا على ستة من أهم المؤشرات الثاملة المعروفة عالمياً كمراجع أسأسية : مؤن

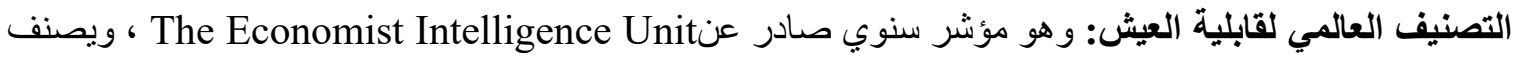

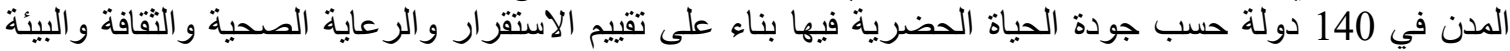

و التعليم والرياضة في والبنية التحتية.

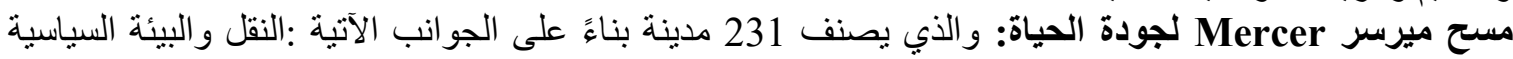

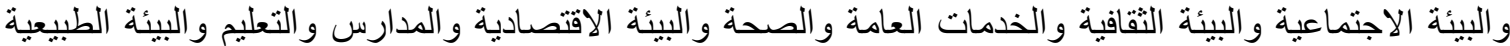

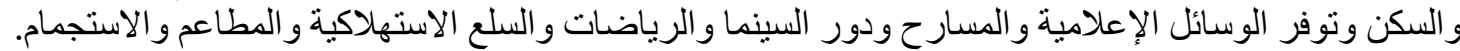

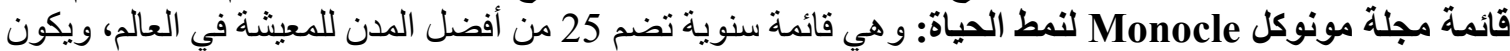

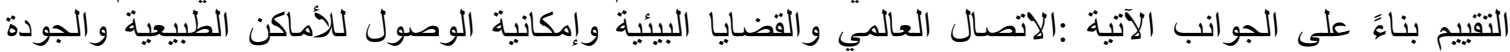

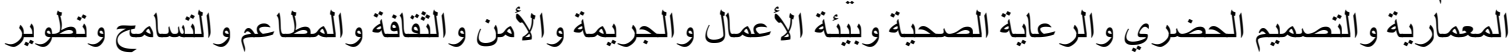
السياسات المبادرة.

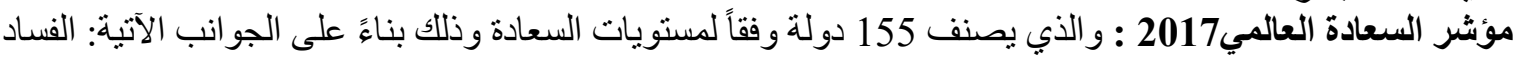

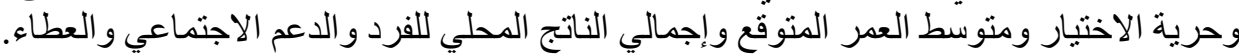

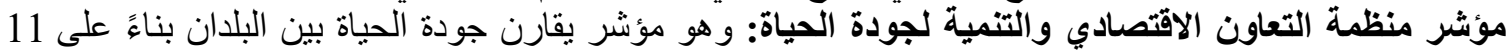

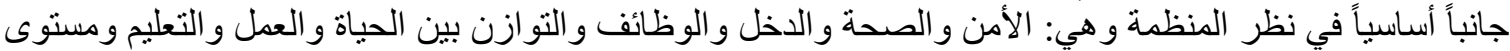

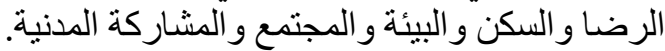

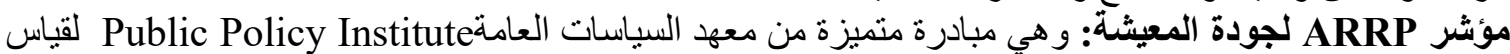

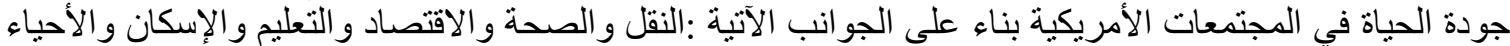

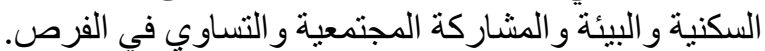

ب/ ا تعريف الفر اغات الحضرية:

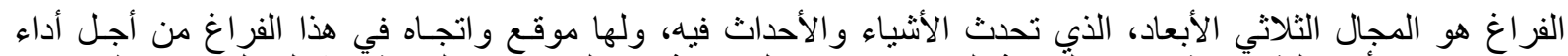

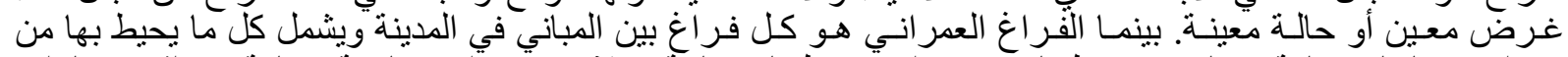

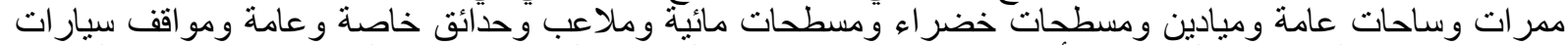

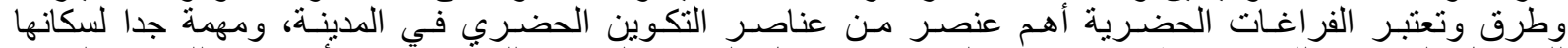

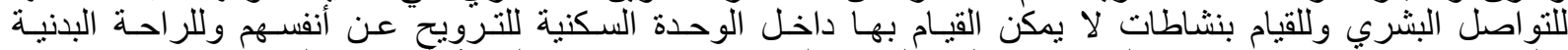

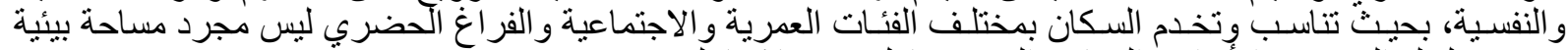
وحسب بل له العديد من الأنو اع و والمعايير النتي سنحاول سردها كما يلي:

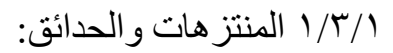

هي مساحة من الأرض مزروعة بصورة طبيعية أو قد تكون من صنع البشر بمختلف أنواع النباتات من الأزهار إلى لماتى

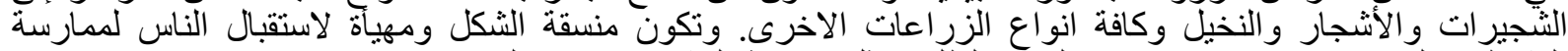

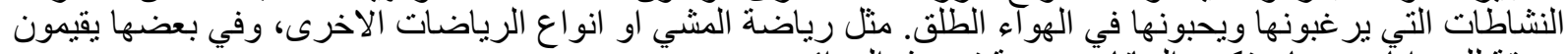
حديقة للحيو انآت ير وعادة تكون النباتات محمية في هذه الحدائقي.

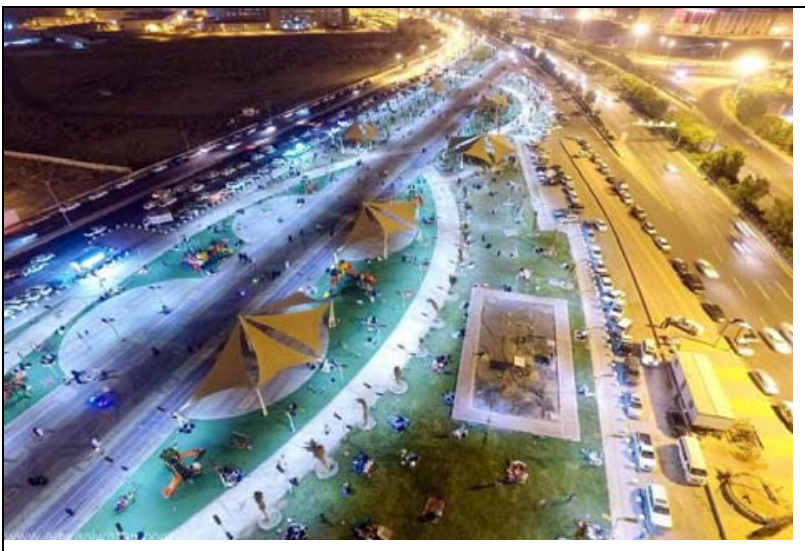

شكل رقم r حديقة الحسينية بمكة المكرمة

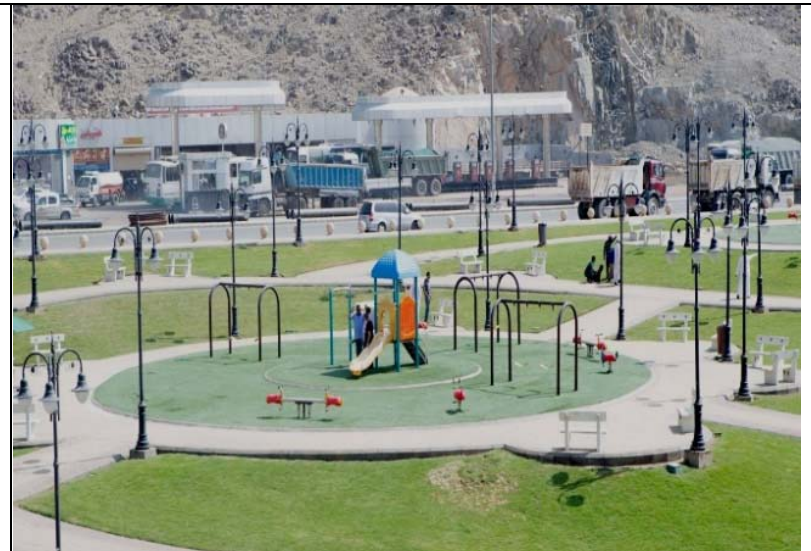

شكل رقم 1 حديقة بمدينة مكة المكرمة داخل احد الاحياء السكنية 


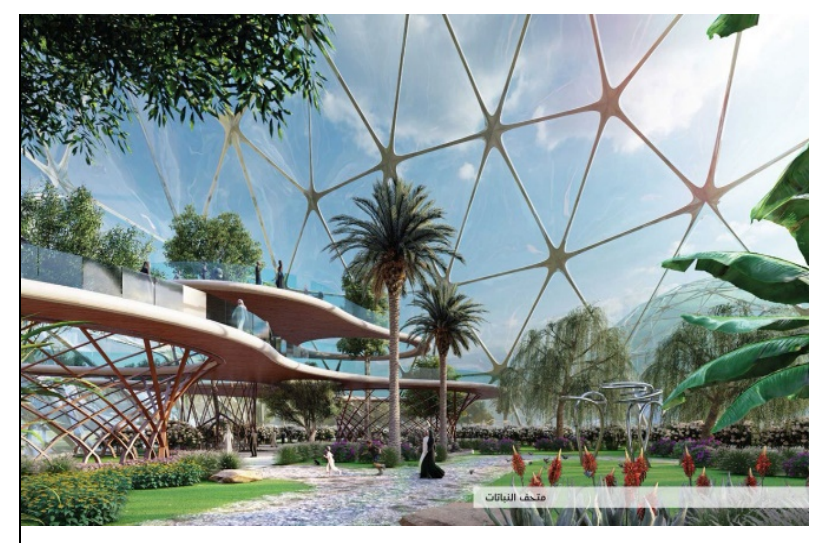

شكل رقم ع متحف النباتات بالرياض

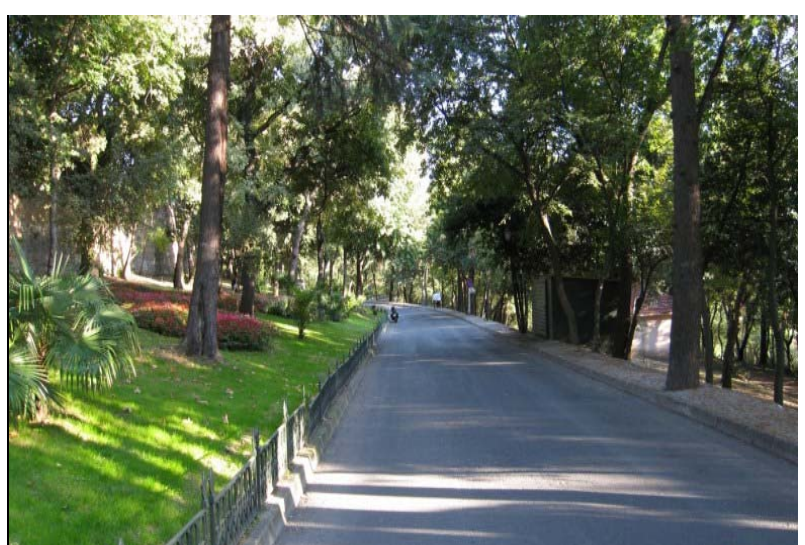

شكل رقم ب حديقة بمدينة جدة

ا 1/T/r الفر اغات العامة المفتوحة و عناصر ها:

هي عبارة عن متنفس طبيعي للسكان سواء على مستوى المدينة او الحي السكنى او المجاورة السكنية ويعمل على عملية توآزن البناء الحضري في المدينة وأيضاً يحافظ على مستوى البيئة و الجانب الصحي للسكان.

\section{r/ كيفية قياس جودة الحياة من خلال المؤشرات الحضرية:}

نود التنويه في هذا البحث على ان المسطحات الخضر اء و المنتزهات هي من المؤشر ات ات الرئيسية لقياس مدى جودة الحياة

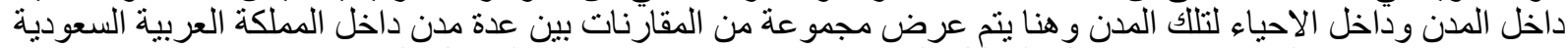

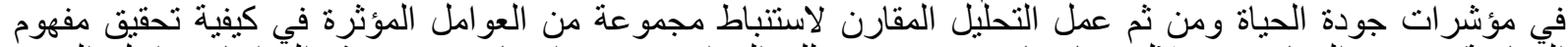

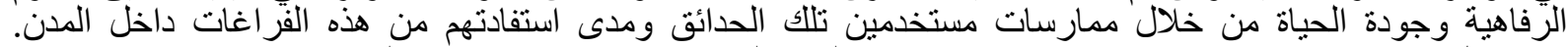

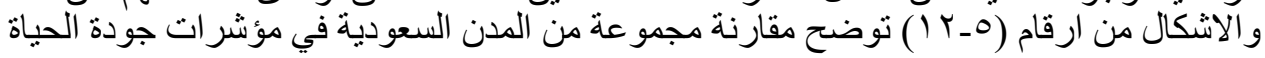

\begin{tabular}{|c|c|c|c|c|c|c|}
\hline الطائف & جدة & ال الدمام & المدينة & مكة & الرياض & اسم المؤشر الرئيسي \\
\hline 20.35 & $r \Delta, 0$ & 42.9 & 17.7 & 34.7 & 20.8 & الكثافة السكاتية فرد / هكتار \\
\hline
\end{tabular}

الكثافة السكانية فرد / مكتار

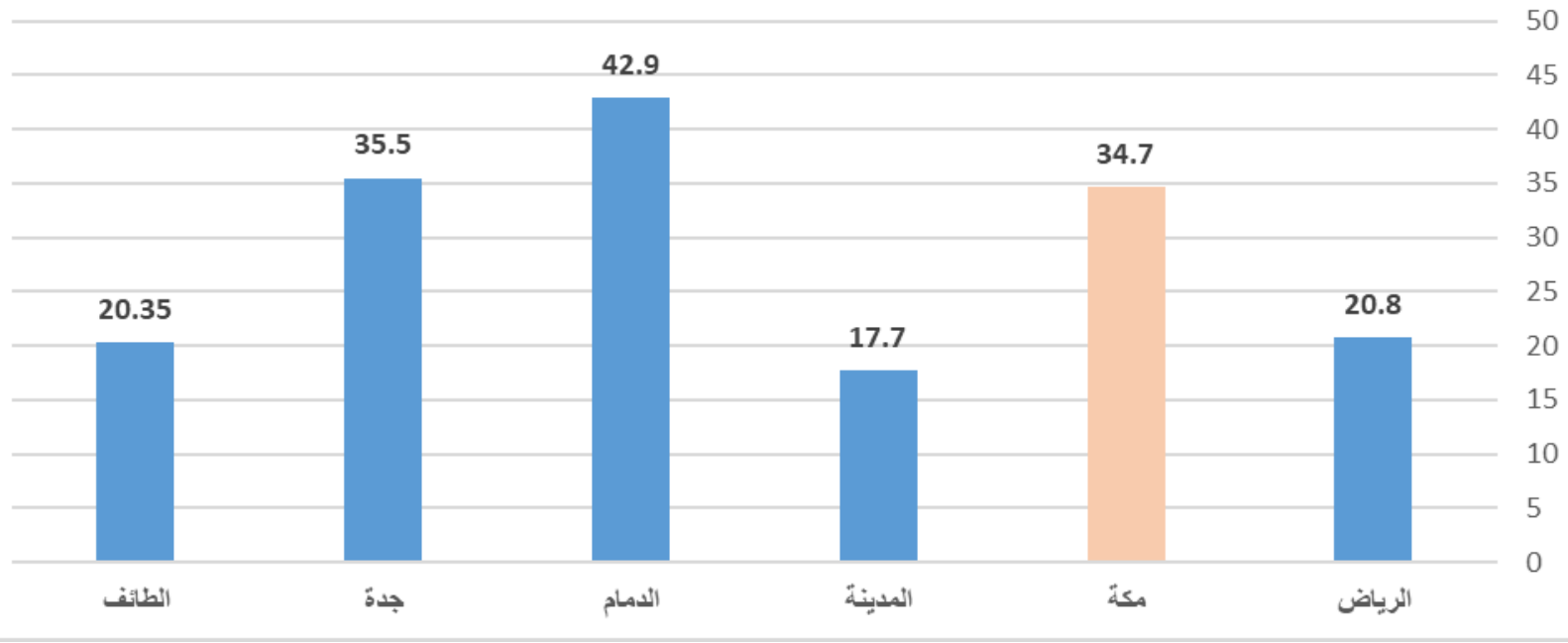

شكل رقم • يوضح مقارنة الكثافات السكاتية بين مجموعة من المدن السعودية (مؤشر جودة الحياة)

\begin{tabular}{|c|c|c|c|c|c|c|c|}
\hline بريدة & الطائف & جدة & الدمام & المدينة & مكة & الرياض & اسم المؤشر الرئيسي \\
\hline 3.6 & 2.27 & 2.79 & 3.06 & 3 & 2.5 & 4 & معدل النمو السكاني \% \\
\hline
\end{tabular}




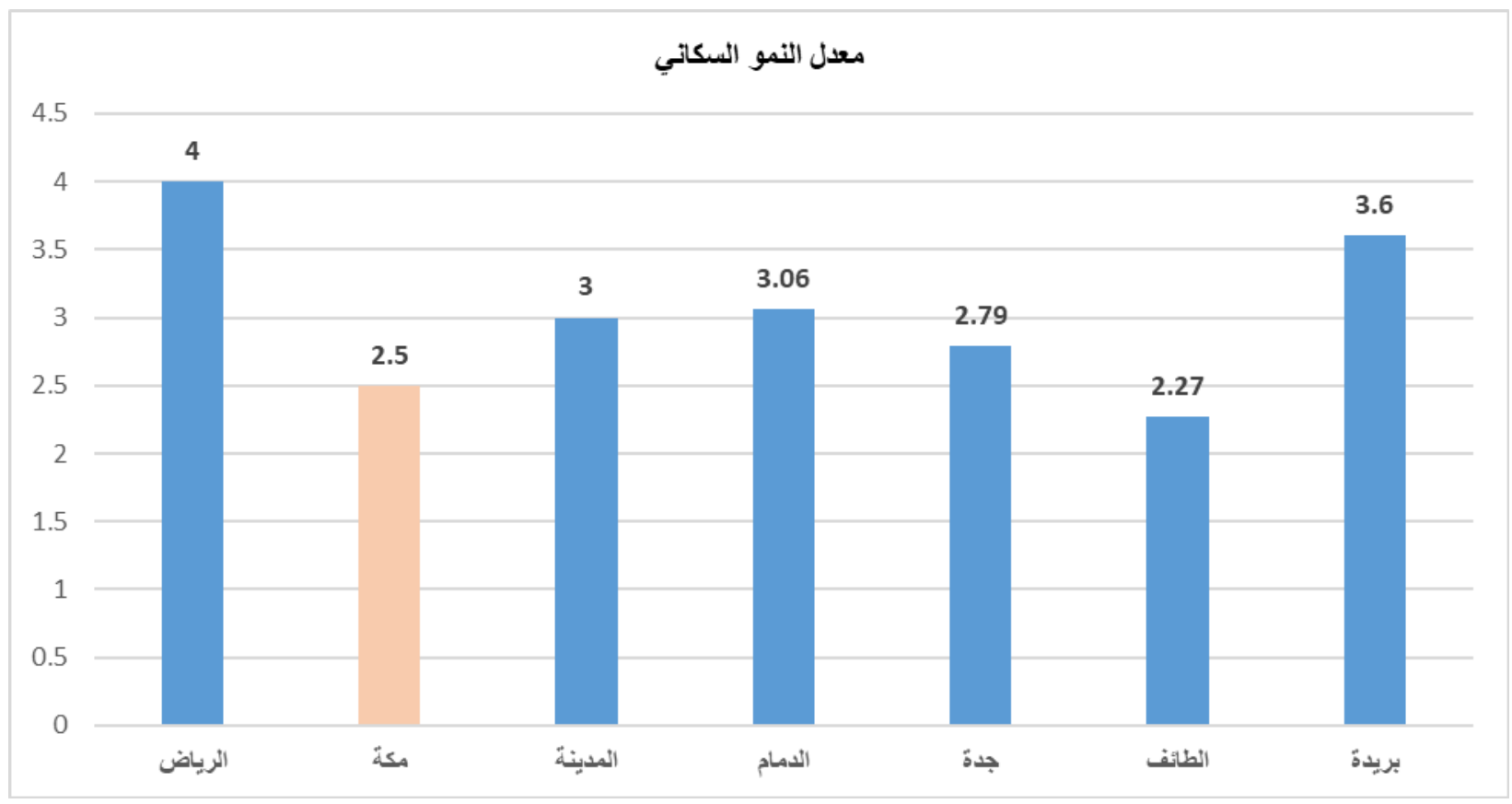

شكل رقم ؟ يوضح مقارنة معدلات النمو بين مجموعة من المدن السعودية (مؤشر جودة الحياة)

\begin{tabular}{|c|c|c|c|c|c|c|c|}
\hline بريدة & الأمام & المدينة & الرياض & الطائف & جلة & ا مكرة & اسم المؤشر الرئيسي \\
\hline 1.95 & 3.2 & 1.7 & 1.08 & 1.69 & 2.17 & 1.2 & من إجمالي مساحة الأنطي (ترفيهي) العمراني مب/فرد \\
\hline
\end{tabular}

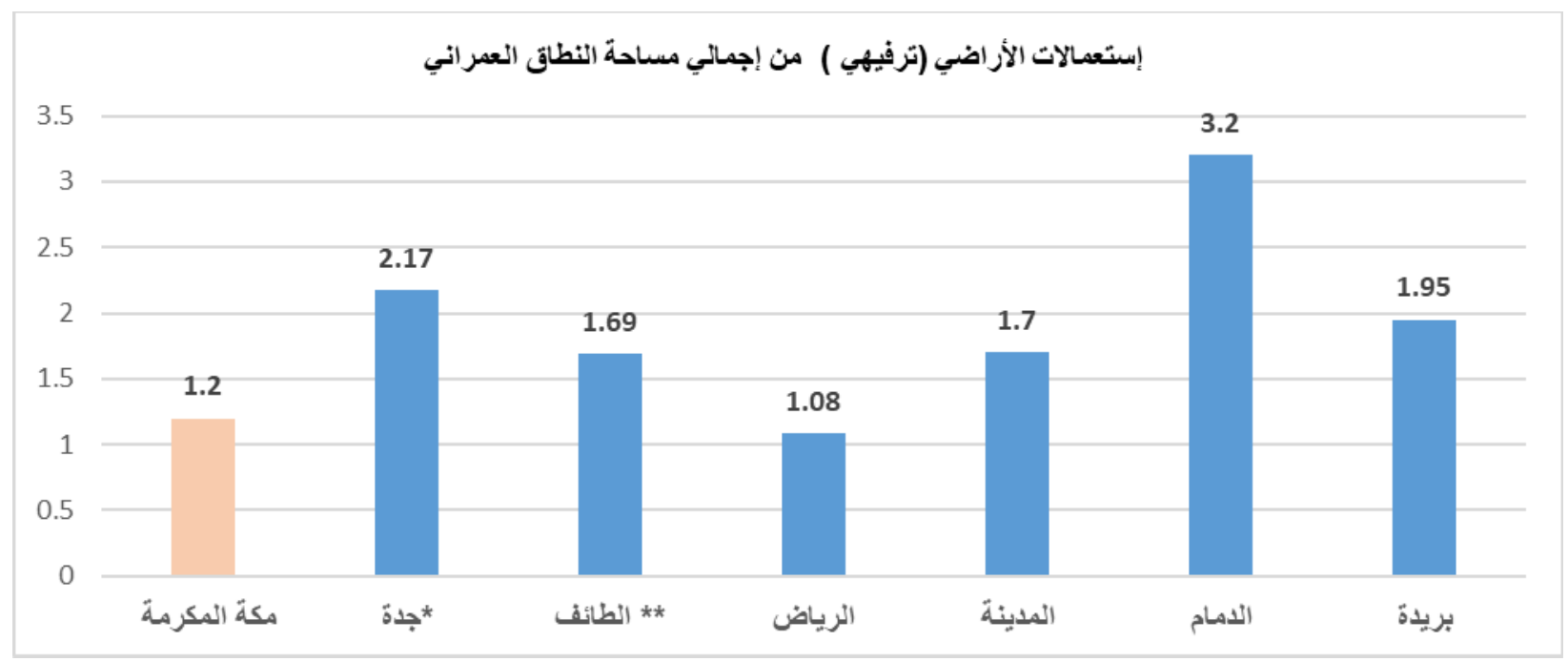

شكل رقم V يوضح مقارنة استعمالات الأراضي الترفيهية بين مجموعة من العدن السعودية (مؤشر جودة الحياة)

\begin{tabular}{|c|c|c|c|c|c|c|c|}
\hline المدينة المنورة & الألمام & بريدة & جدة & مكة المكرمة & الرياض & وحدة القياس & اسم المؤشرَ \\
\hline 19.8 & 22.14 & 15.9 & 23.4 & 27 & 31 & دقيقة & متول زمن زمن الرحلة) \\
\hline
\end{tabular}




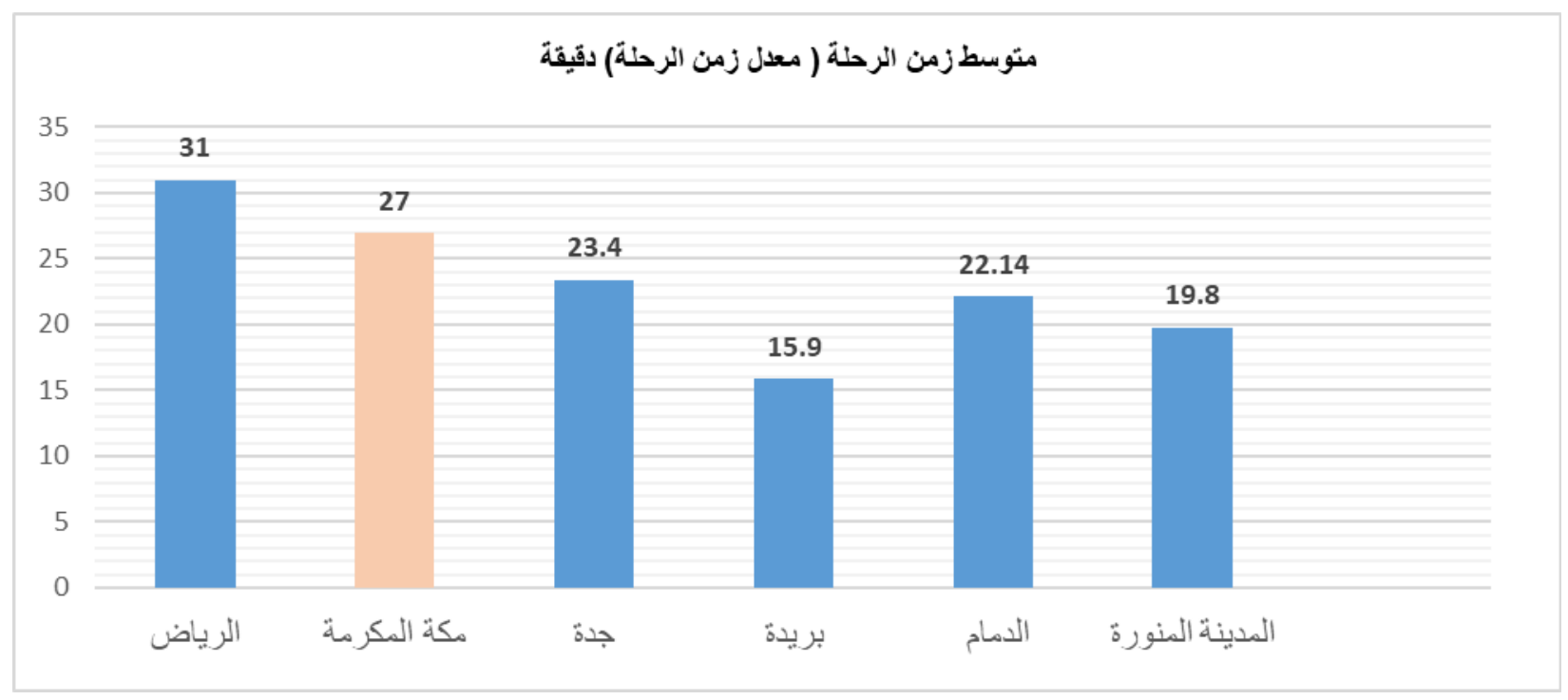

شكل رقم ^ يوضح مقارنة متوسط زمن الرحلة اليومي بين مجموعة من المدن السعودية (مؤشر جودة الحياة)

\begin{tabular}{|c|c|c|c|c|c|c|c|}
\hline الطائف & المدينة المنورة & بريدة & جدة & مكة المكرمة & الرياض & وحدة القياس & اسم المؤشر الرئيسي \\
\hline 39.9 & 85.9 & 89.73 & 86.7 & 68.7 & 98 & نسبة مئوية & خدمات المياه ( مياه \\
\hline
\end{tabular}

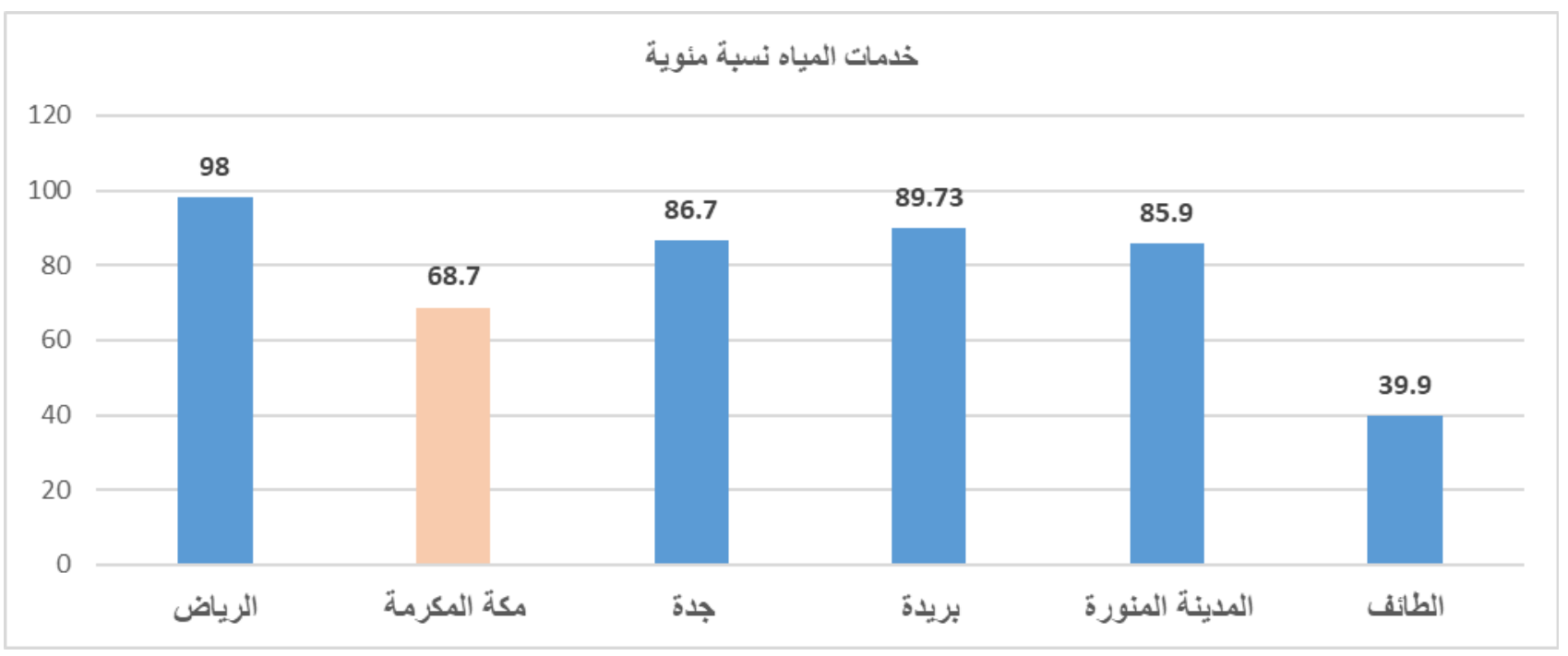

شكل رقم 9 يوضح مقارنة مدى توفر خدمات المياه بين مجموعة من المدن السعودية (مؤشر جودة الحياة)

\begin{tabular}{|c|c|c|c|c|c|c|c|c|}
\hline الطائف & المدينة المنورة & بريذة & الامام & جدة & مكة المكرمة & الرياض & وحدة القياس & اسم المؤشر الرئيسي \\
\hline 27.6 & $\mathbf{5 7 . 8}$ & 74.6 & 10.5 & 40.3 & 63.9 & 84 & نسبة مئوية & شبكة الصرف الصحي \\
\hline
\end{tabular}




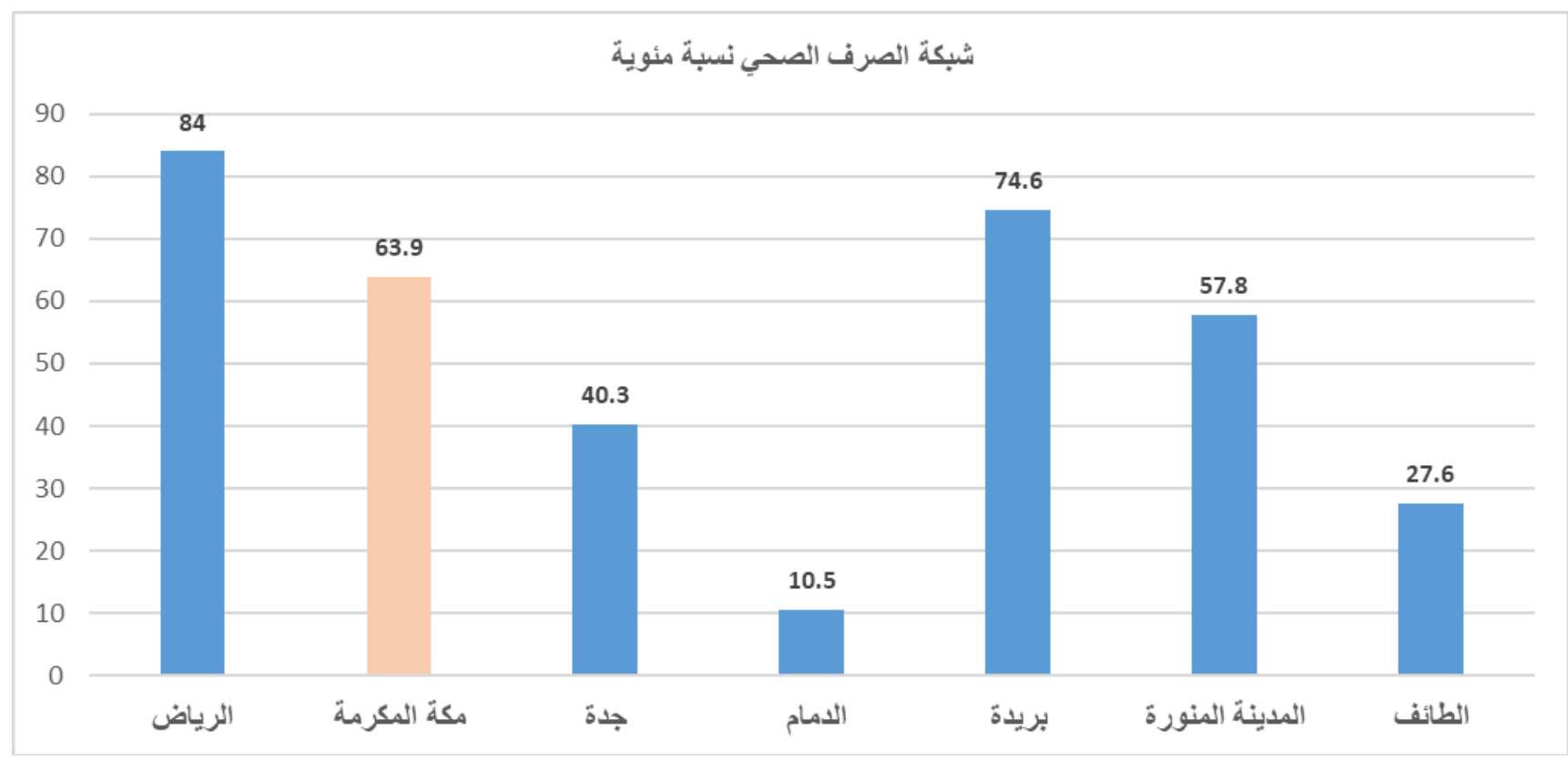

شكل رقم • 1 يوضح مقارنة مدى توفر خدمة شبكة الصرف الصحي بين مجموعة من المدن السعودية (مؤشر جودة الحياة)

\begin{tabular}{|c|c|c|c|c|c|c|c|c|}
\hline الطائف & المدينة المنورة & بريدة & الالدمام & جدة & مكة المكرمة & الرياض & وحدة القياس & اسم المؤشر الرئيسي \\
\hline 100 & 100 & 100 & 100 & 98.1 & 96.5 & 99.9 & نسبة مئوية & شبكة الكهرباء \\
\hline
\end{tabular}

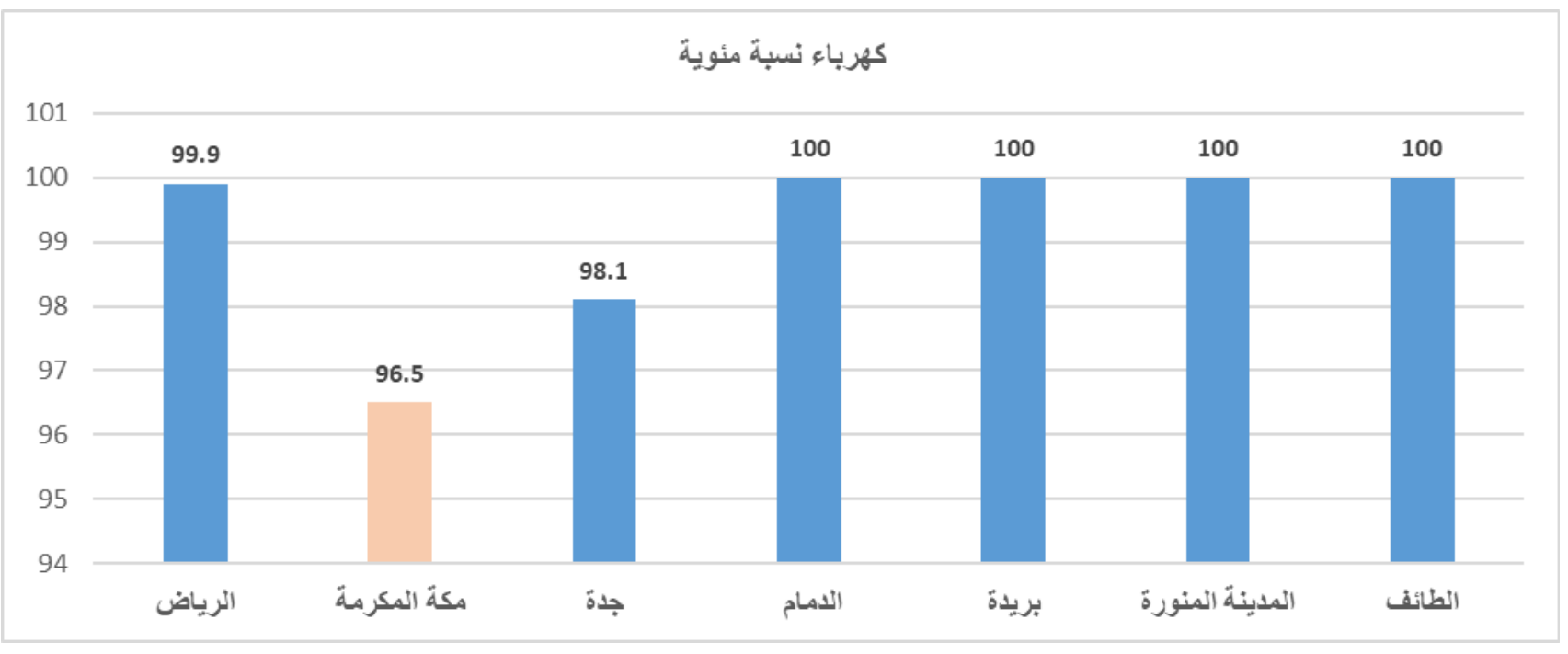

شكل رقم 11 يوضح مقارنة مدى توفر خدمة شبكة الكهرباء بين مجموعة من المدن السعودية (مؤشر جودة الحياة)

\begin{tabular}{|c|c|c|c|c|c|c|c|}
\hline المدينة المنورة & ابها & الامام & 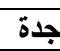 & مكة المكرمة & الرياض & وحدة القياس & اسم المؤشر الرئيسي \\
\hline 5.1 & 11.7 & 3.7 & $7, V$ & $r, v q$ & 7.2 & متر مربع & الصسيب الفرات الخضر اء من \\
\hline
\end{tabular}




\section{نصيب القرد من المسطحات الخضر ائم2}

11.7
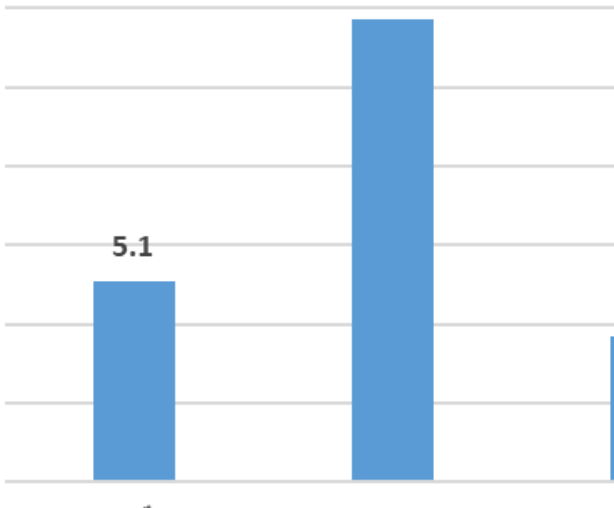

المدينة المنورة

ابـان

الدمام
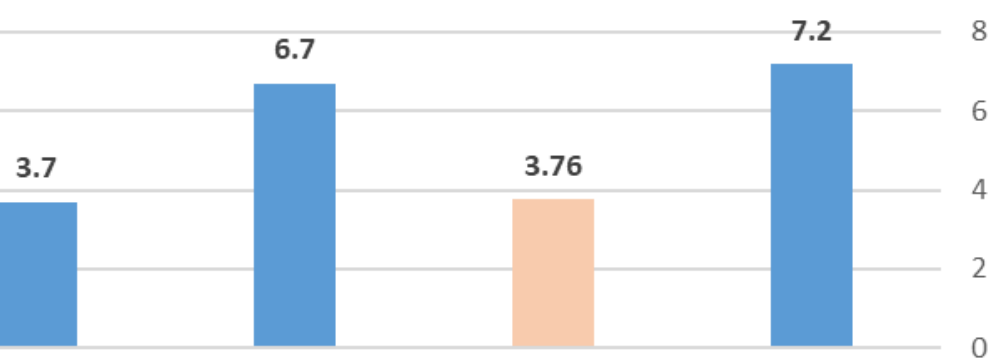

شكل رقم r 1 يوضح مقارنة نصيب الفرد من المسطحات الخضراء (مؤشر جودة الحياة)

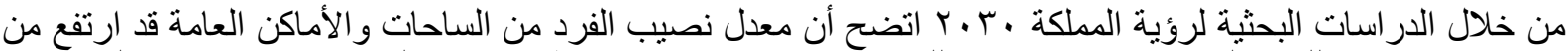

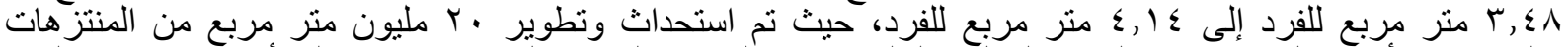

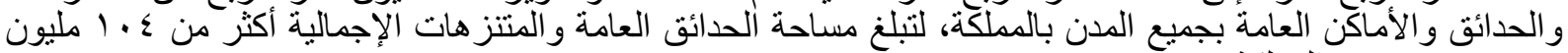
متر مربع في مدن المملكة.

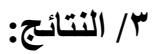

ركزت الدراسة البحثية على مجمو عة من المؤشرات ذات العلاقة القوية مع الاماكن العامة والمفتوحة ونسبة المسطحات

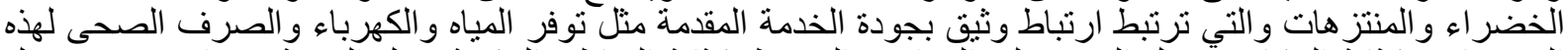

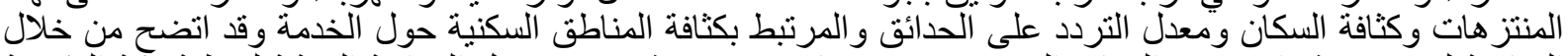

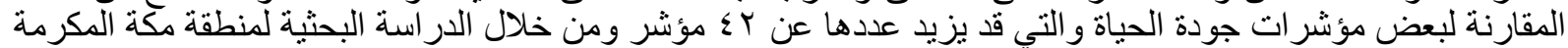

ما يلي:

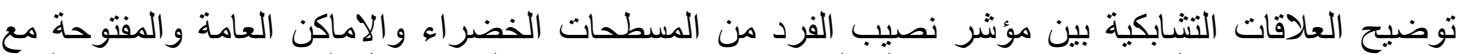

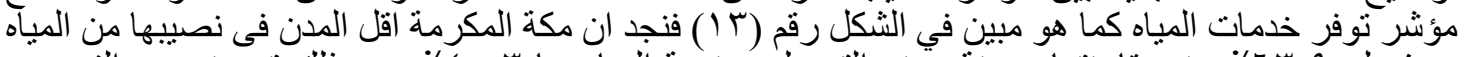

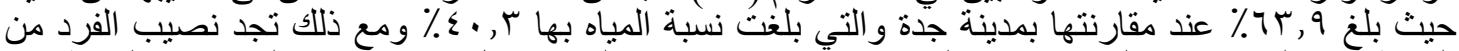

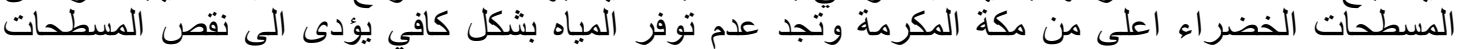
الخضر اء.

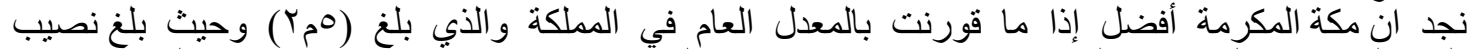

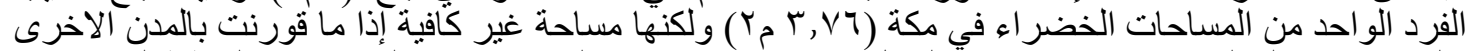

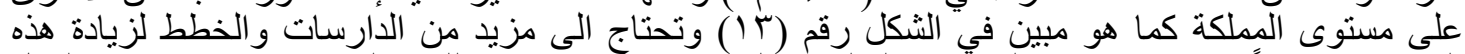

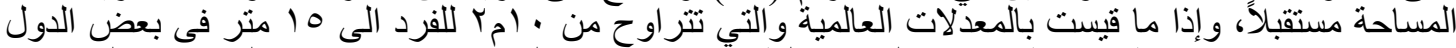

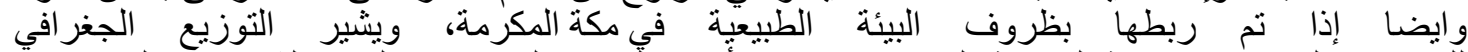

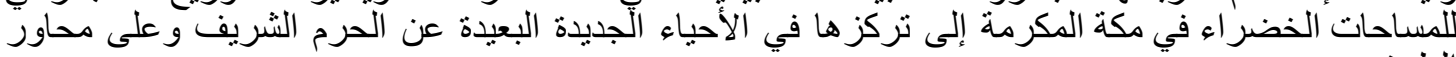

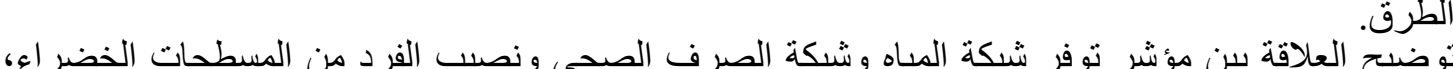

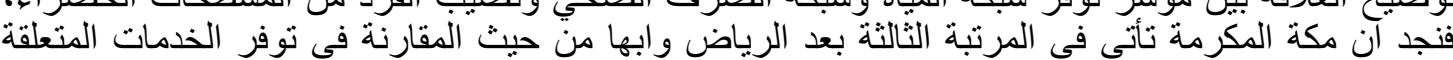

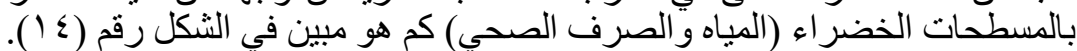

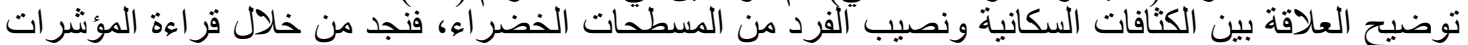

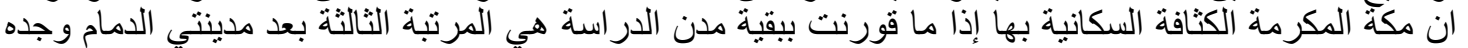

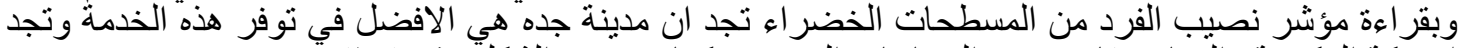

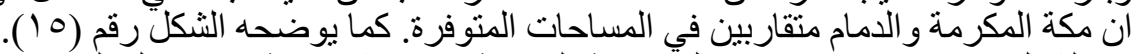

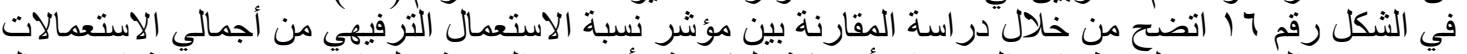

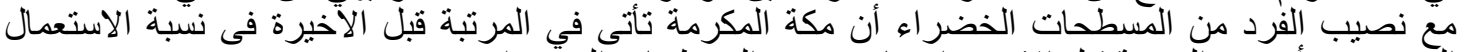

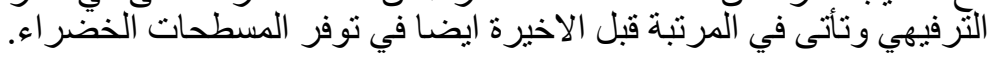




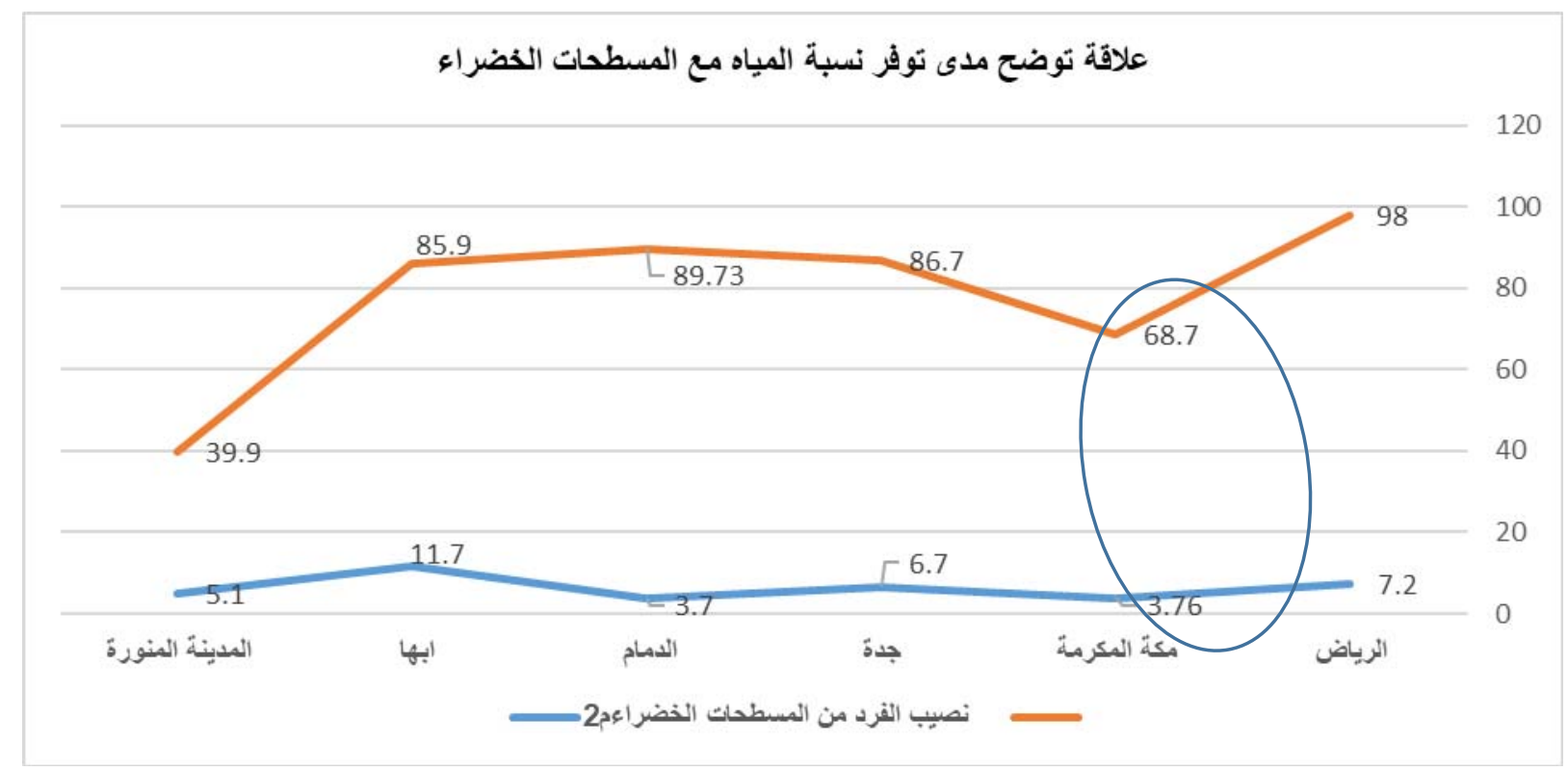

شكل رقم ب ا يوضح علاقة مدى توفر نسبة المياه مع المسطحات الخضراء

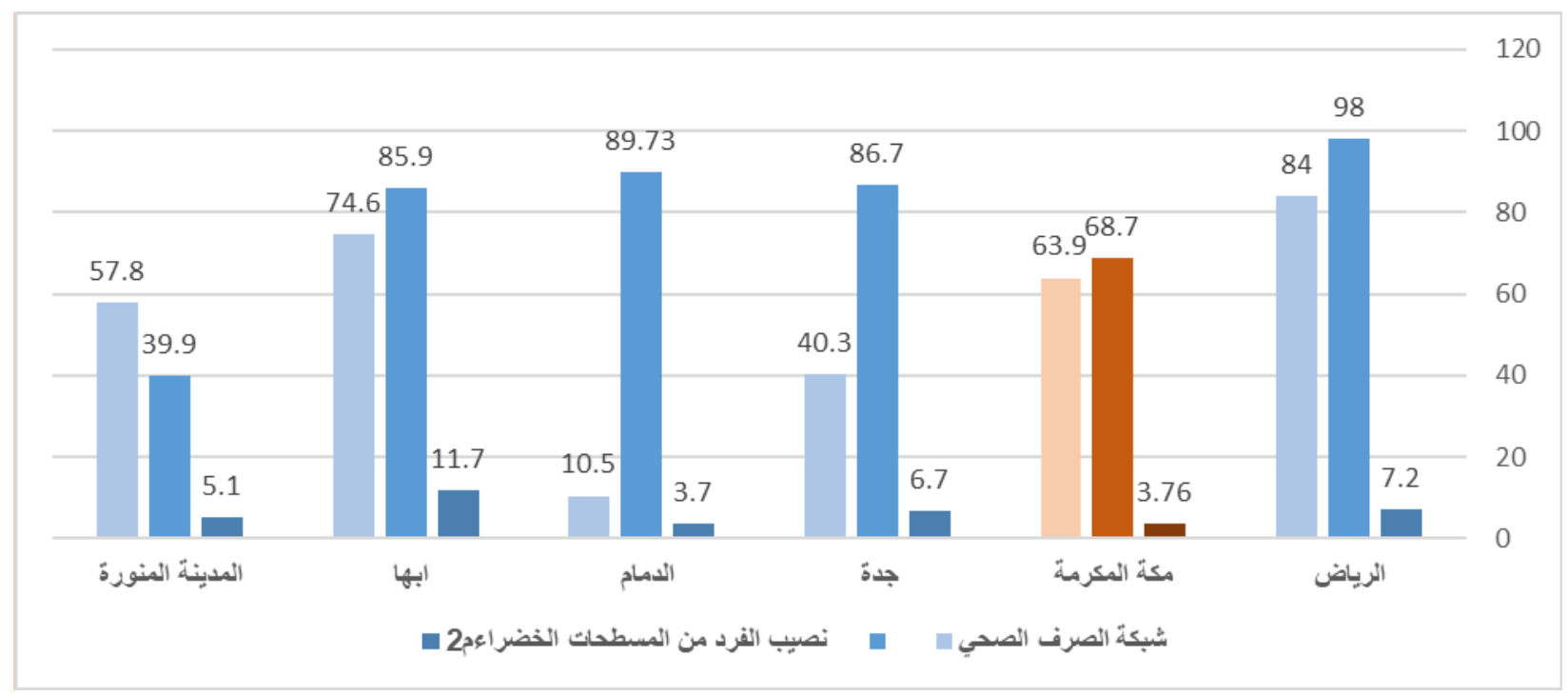

شكل رقم ؛ 1 يوضح علاقة مدى توفر نسبة المياه والصرف الصحي مع المسطحات الخضراء

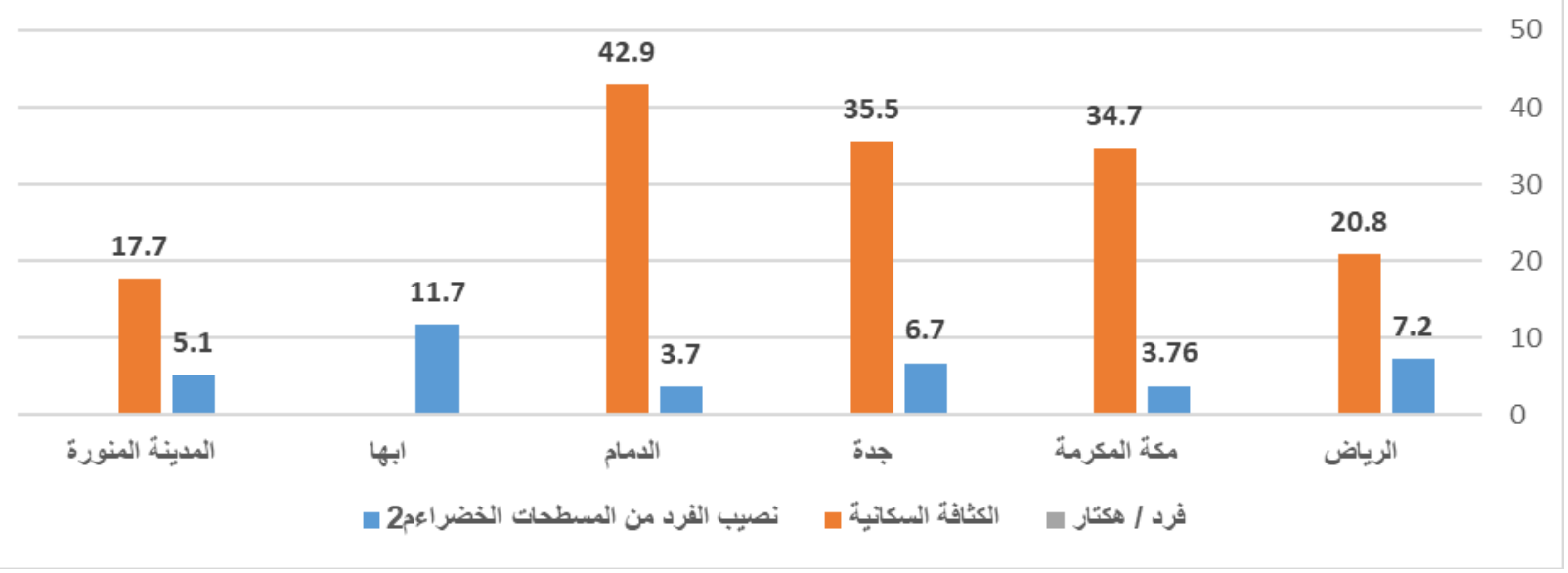

شكل رقم ه ايوضح علاقة توضح الكثافات السكانية مع المسطحات الخضراء 


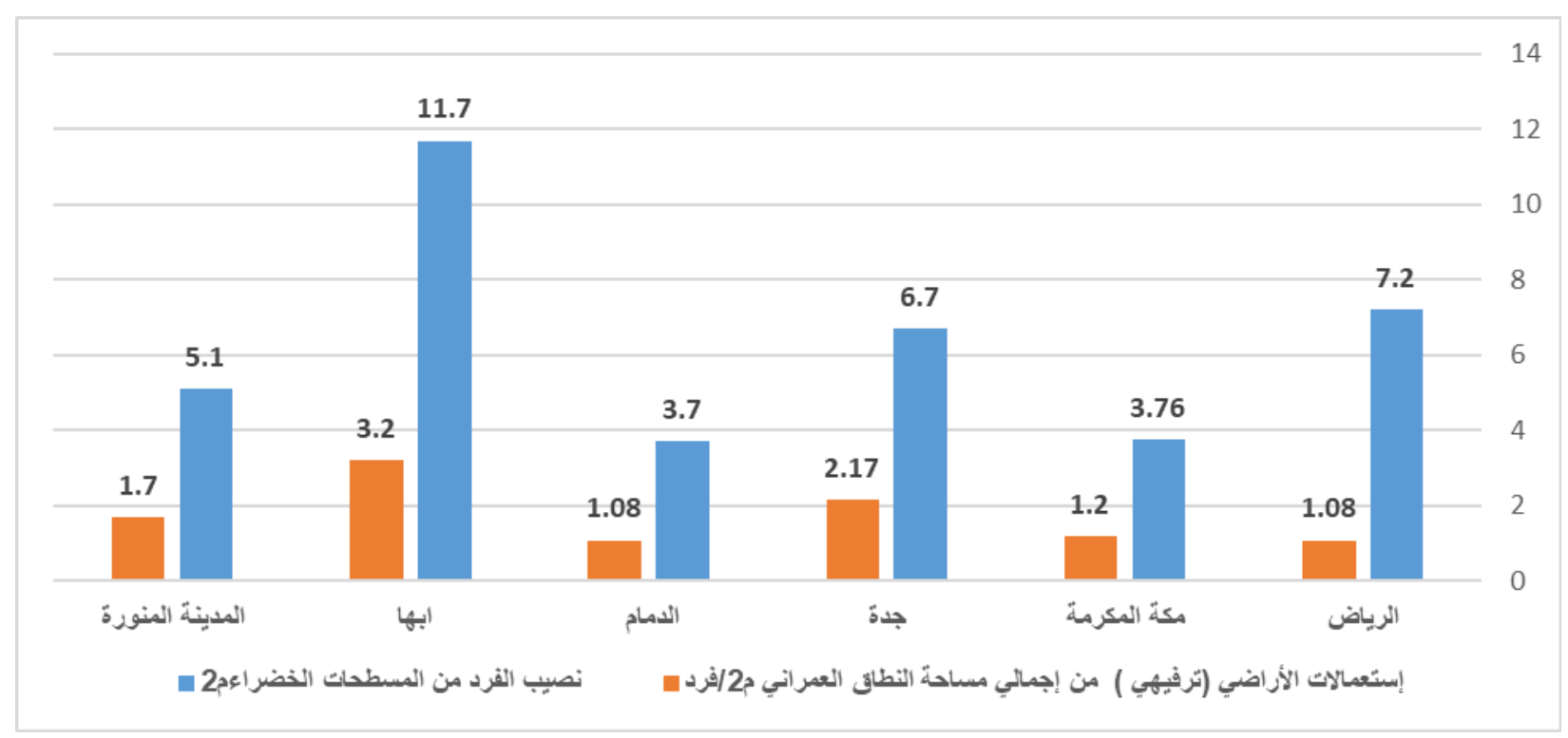

شكل رقم 1 ايوضح علاقة توضح نسبة الاستعمال الترفيهي من أجمالي الاستعمالات مع نصيب الفرد من المسطحات الخضراء

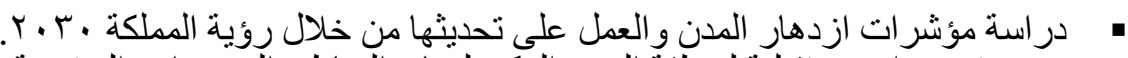

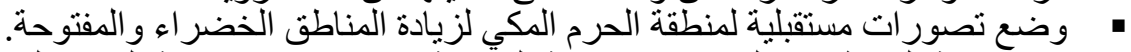

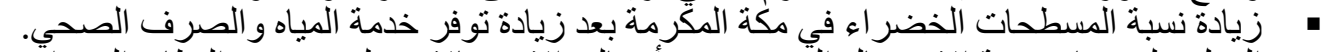

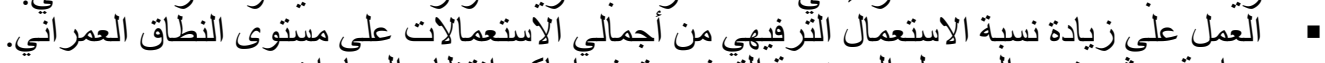

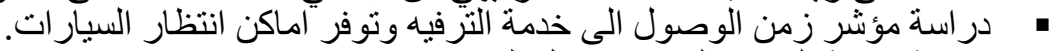

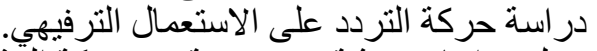

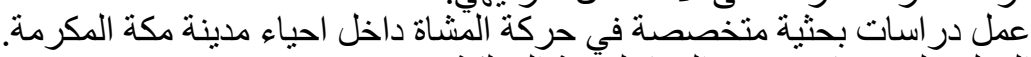

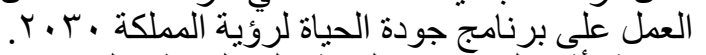

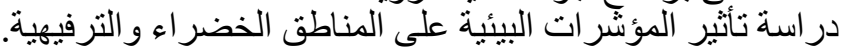

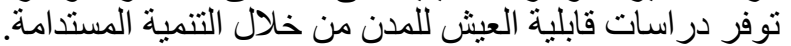
در اسة نسبة رضنا المو اطنين على جودة الحياة داخل المدينة (مكة المكرمة). 


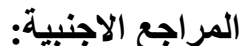

[1] https://www.lincolninst.edu/sites/default/files/pubfiles/making-room-for-a-planet-ofcities-full 0.pdf

[2] https://unhabitat.org/sites/default/files/download-manager-files/CPI-Arabic.pdf

[3] https://unhabitat.org/sites/default/files/2020/04/taryr halt azdhar_almdn altayf 2019.pdf

[4] https://unhabitat.org/sites/default/files/2020/04/tqryr_halt_azdhar_almdn_mkt 2019.pdf

[5] https://www.kau.edu.sa/Files/320/Researches/72736 45889.pdf

[6] https://www.futuresaudicities.org/wp-content/uploads/2017/07/Intsitutional-ReportAr-V1-18.1.17.pdf

[7] Policy Focus Report • Lincoln Institute of Land Policy

[8] Making Room for a Planet of Cities

[9] Shlomo Angel with Jason Parent, Daniel L. Civco, and Alejandro M.Blei , 2001. 